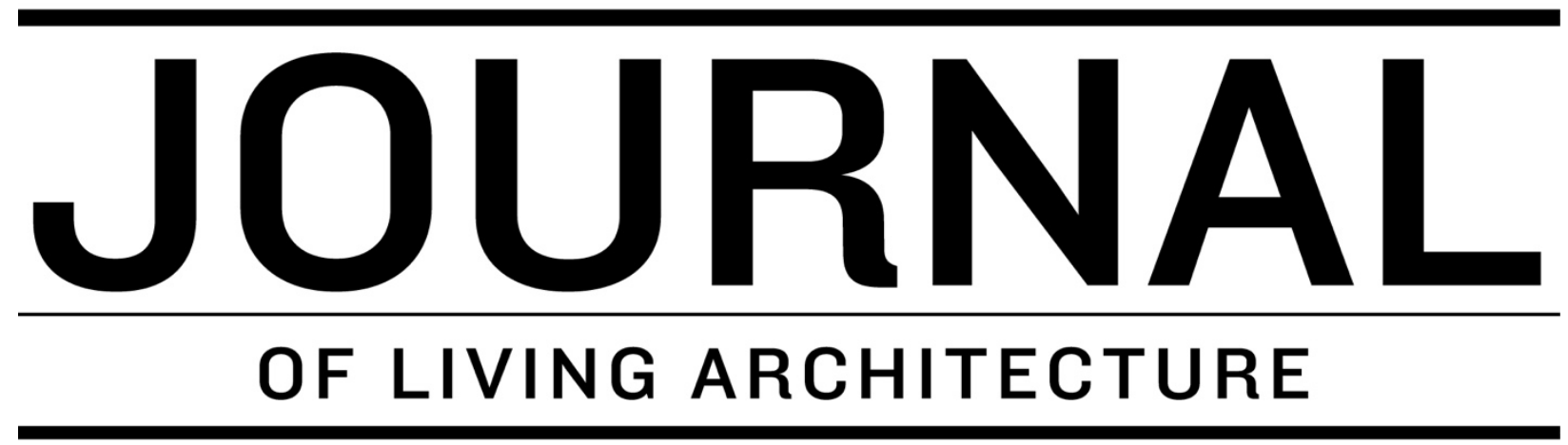

A GREEN ROOFS FOR HEALTHY CITIES PUBLICATION

\title{
Deploying living walls as kinetic facades
}

\author{
Leann Andrews, PLA, ${ }^{1,}$, Nancy Rottle, PLA, FASLA ${ }^{2, ~ *}$ \\ ${ }^{I}$ PhD Candidate, College of Built Environments; Researcher, UW Green Futures Lab, University of \\ Washington, USA \\ ${ }^{2}$ Professor, Department of Landscape Architecture; Director, UW Green Futures Lab, University of \\ Washington, USA
}

*corresponding authors: andrewsl@uw.edu,nrottle@uw.edu

\begin{abstract}
This paper explores ideas for integrating moveable exterior living walls with the facades of high-rise buildings to enhance urban ecosystems while contributing opportunities for personal interaction with the natural world. Rethinking the typical static nature of living walls, kinetic green walls convey a dynamic aesthetic that provides multiple potential benefits including habitat, passive cooling and opportunity for personal expressions in dense urban environments. This article proposes prototypes of kinetic green walls and suggests their expanded application to the ultra-urban built environment. It offers a preliminary typology, presents a moveable green wall system prototype installed in an urban university setting in Seattle, and demonstrates how the kinetic qualities afford flexible operational, educational, and aesthetic functions. Reflecting upon the challenges and solutions for the built project, this article identifies essential considerations for designing and constructing moveable living walls, illustrated through photographs, construction details and diagrams of new kinetic living wall applications.
\end{abstract}

Key words: moveable living walls, kinetic facades, sliding green wall, access to nature, sustainable design, maintenance access 


\section{INTRODUCTION}

Today's increased urbanization encourages us to dwell in smaller residences and workplaces, intensifying our population in multi-story urban enclaves. However, this dense urban living separates us from the ground and from the vegetative world, depriving urbanite populations from nature's documented benefits, which range from nutrition for the body to relaxation and stress reduction for the mind. Integrating living walls with the facades of high-rise buildings may be one solution to mitigate the nature-deprivation that urban living produces.

Constructed green walls across Europe, Asia, North and South America exemplify the potential multiple benefits green walls contribute to urban environments, including noise attenuation, air purification and cooling, energy savings, habitat, and aesthetics (Azkorra et al 2015, Chen et al 2013, Lianga et al 2014, Pulselli et al 2014, Safikhani et al 2014, Sutton 2014, Francis 2011, Wong et al 2010, Williams 2010). Parallel research on the ecosystem services of green roofs suggests that green walls may provide similar ecological benefits such as stormwater management, energy conservation and habitat provision (Oberlander et al 2007). Further, extensive documentation of the benefits of human contact with nature that support theories of biophilia would indicate that interaction with green walls - whether visual, olfactory or interactive - contribute to human health and well-being. (Wolf et al 2014, Beatley 2011, Kellert et al 2008.) However, access to upper story walls can be a challenge, limiting interaction with these living features to professional designers, installers, and maintenance workers, and requiring elaborate safety equipment to lift workers from the ground or dangle them from the roofs of tall buildings for both construction and on-going care. The result - at best - is that the urban resident, student or office worker is kept at arm's length from the plants growing on the wall, and the nature that they invite, and at worst, that upper walls become neglected and perish due to lack of easy attention. Designing mobility into green wall systems makes it possible to move walls into favorable growing or viewing conditions and then back to within easy reach for maintenance, harvesting, study or appreciation.

\section{POTENTIAL APPLICATIONS OF KINETIC LIVING WALLS}

Typically, the human is seen as the mobile element to gain access to static green walls. But, what if the wall itself is made moveable? The flexibility of a living wall design that possesses capacity for dynamic mobility suggests numerous applications on structures of varying types and heights. Moveable living walls can be used for shading walls, windows and doors; for providing gardening, food-growing and learning opportunities for occupants of multi-story buildings; and for access to set up and maintain habitat features such as bird perches and bee boxes or elements of personal expression such as garden ornaments, painted frames or custom plantings. We can imagine a series of kinetic habitat walls on high-rise structures to provide vertical "pollinator pathways," (Bergmann 2015), habitat "stepping stones" between ground plantings and living roofs, and opportunities for apartment dwellers to engage with custom plantings and green wall features. Likewise, a series of moveable walls might be actively farmed to produce marketable agricultural products.

Based on these potential performances, kinetic panels may take a variety of forms and moveable mechanisms, to provide the multiple functions of shading combined with growing 
plants for a variety of purposes. We offer a preliminary typology, based simply on the movement enabled within the wall motion. Variations of this typology are outlined below and shown in three configurations in Figure 1. These particular applications are for exterior conditions with potential for interior and balcony interactions.

A. The Hinged Green Window Wall: Shutters on windows could be hinged so they can be moved to face inward into an open window space (Figure 1, Top). Such designs could allow herbs and greens to be grown on the wall facing outward, and then swung inward for harvesting, maintenance or learning. Such a feature could be ideal for high-rise apartment living with limited gardening opportunities. A similar application at the USA Pavilion for Expo Milano explores a hinged vertical farm.

B. The Sliding Balcony Door Green Wall: Sliding panels could be located adjacent to balconies for growing food, ornamentals, and native plants to support insect and avian use, and then slid or pivoted to the balcony for maintenance and harvesting access (Figure 1, Middle) Such living panels on a track or hinge could also be used to block solar radiation from transparent windows and doors, keeping interior rooms cooler during the heat of the day. Panels with slots for air passage could even cool the air before entering the room, essentially acting as a passive air conditioner.

C. Folding Green Brise-Soleil: Living panels could be integrated with brise-soleils (shading devices) to block direct sunlight from entering through windows or glass doors by using various types of folding articulated arms (Figure 1, Bottom). Access to the growing surface could be gained from an open window or mini-balcony, with a folding or hinged armature mechanism to lower horizontal shades over doorways or windows. As in the Hinged Green Window Wall, the device could also be vertical, moved to block unwanted direct sunlight from entering interior spaces. Such shading devices could also be solar-controlled, such as at Santiago Calatrava's celebrated brise-soleil at the Milwaukee Art Museum where the mechanism operates on a grand scale, or the solarized vertical window shades on the Copenhagen Business School "Wedge" building designed by Lundgaard \& Tranberg.

A few moveable living wall installations exist to date, including the living partition installation, "The Great Barrier" at the Metreon Center, San Francisco, designed by Habitat Horticulture, as well as commercial rolling planter products such as the MEWU mobile urban farming planters and Dublin's Maximize Design moveable planter walls. As noted above, the USA Pavilion for Expo Milano designed by Biber Architects, Dlandstudio and team features an urban farm with heirloom plants growing on hinged panels, recalling the history and future of the country's relationship with agriculture.

From these three types of applications, a modification of the Sliding Balcony Door Green Wall concept was selected for fabrication and installation. This concept allowed for the best opportunity to test the integration of service and research personnel access, the kinetic sliding structural systems, electrical and irrigation, plants and growing media. The following section describes this prototype application at an urban university setting in Seattle. 


\section{Hinged Green Window Wall}

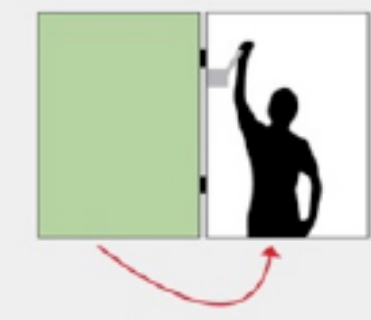

elevation diagram

\section{Sliding Balcony Door Green Wall}

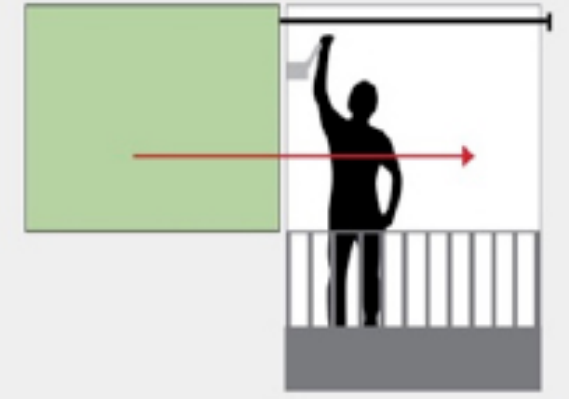

elevation diagram

\section{Folding Brise Soleil}

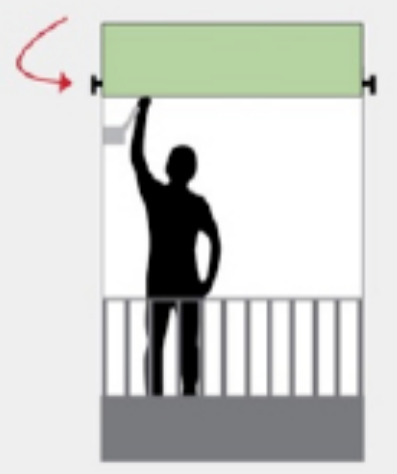

elevation diagram
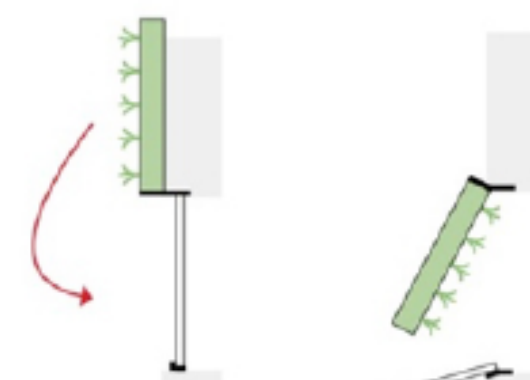

plan view diagrams
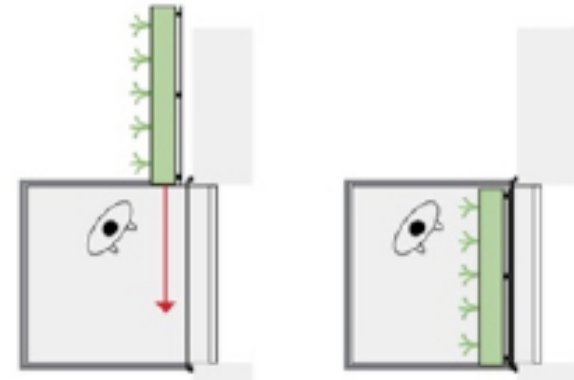

plan view diagrams
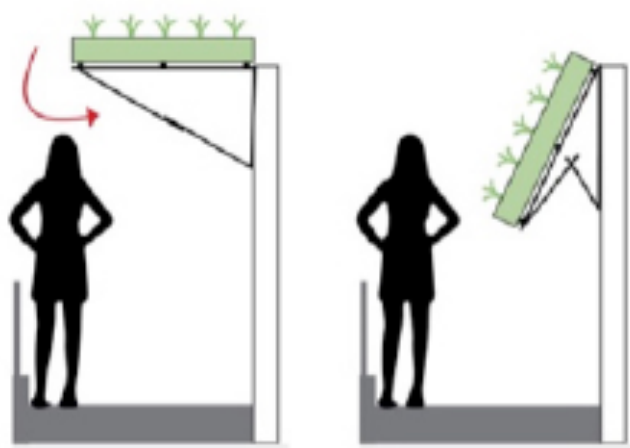

section elevation diagrams

Figure 1: Design possibilities for moveable green walls: Top) Hinged Green Window Wall, Middle) Sliding Balcony Door Green Wall, and Bottom) Folding Brise Soleil 


\section{GOULD HALL SLIDING GREEN WALL}

\section{Materials}

The Gould Hall Green Wall (Figure 2) was installed in 2012 on a university building at the University of Washington (UW) in Seattle, in a dense urban area. This moveable green wall was designed by the UW Green Futures Research and Design Lab (GFL) and contractor SolTerra Systems with the purpose of acting as an outdoor classroom (for courses across disciplines such as landscape architecture, architecture, urban ecology, urban design etc.) and serving as a research case (to learn the design parameters for living walls and to understand how green walls can address biodiversity, the urban heat island effect, building performance, and water harvesting and reuse). The design program included two, 10-foot x10-foot sliding green wall panels, planting substrate, plants suitable for an east-facing wall, a water harvesting and irrigation system, and lighting. The green wall conceptually responds to design features used in the courtyard below (i.e. Corten panels, plant species, framing), extruding the garden up the face of the building. The design, construction and maintenance of the Gould Hall Green Wall was documented by videos, systematic photographs and field observations, and a log by the project team over the course of four years, from 2011-2015. The design goals responded to several critical considerations established by the proponents and advisors for the Green Wall-including Gould Hall professors, the GFL research team, university professional personnel and maintenance staff-outlined below.

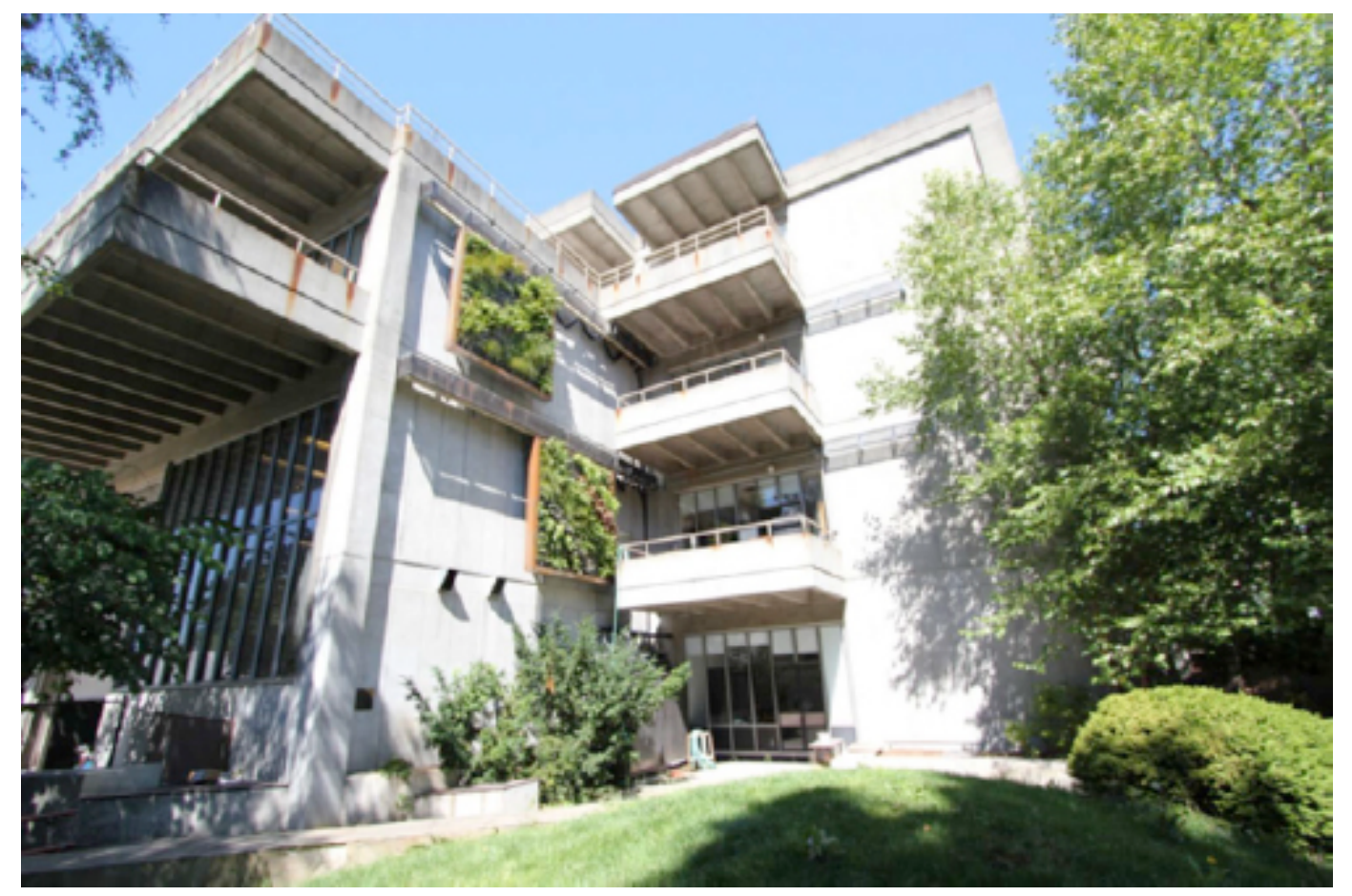

Figure 2: The Gould Hall Green Wall hangs on a moveable track where the walls can be accessed from the adjacent balconies for maintenance, monitoring and learning.

\section{Access}

The inspiration for the mobility aspect of the green wall was access for maintenance, monitoring and education. Maintenance activities include quarterly weeding, plant inspections and parts 
repairs. Monitoring for a related research project included accessing temperature and water sensors, and inspecting walls for insects, bird activity, nests, and plant health. Education activities include lectures on the green wall during student classes, tours for local professionals looking to design green walls in their own practice, and training courses to university staff to learn about sustainable design. The design for the two green wall panels on the second and third stories of the host building required access through a constricted garden portal, precluding the use of a cherry picker to reach the walls; additionally, that approach would have required removing the mature yews at the base of the east-facing concrete façade, thereby actually reducing biomass and habitat in the garden rather than increasing it. Safety parameters disallowed repelling from the building's aging balcony, according to policy established by university safety personnel.

\section{Movement Systems}

The solution to the access challenge, an outcome of a design workshop process involving faculty, students and staff, was to hang the walls on a track along which they move, powered by a hand crank to pull them to the adjacent balconies where they can be accessed for maintenance, monitoring and learning. (Figure 3, left) The hanging track mechanisms are the same as those employed on barn or sliding garage doors, specified to be supplied by Richards-Wilcox Hardware. These consisted of a truck hanger assembly with a hanging bracket and guide track rollers, attached to the Corten steel and aluminium green wall frame. Wire cables located on the adjacent balconies and connected to winches with hand cranks, maneuver the walls. (Figure 3, right) The tracks are slightly sloped to allow the weight of the walls to pull them back into place once the crank is given slack.

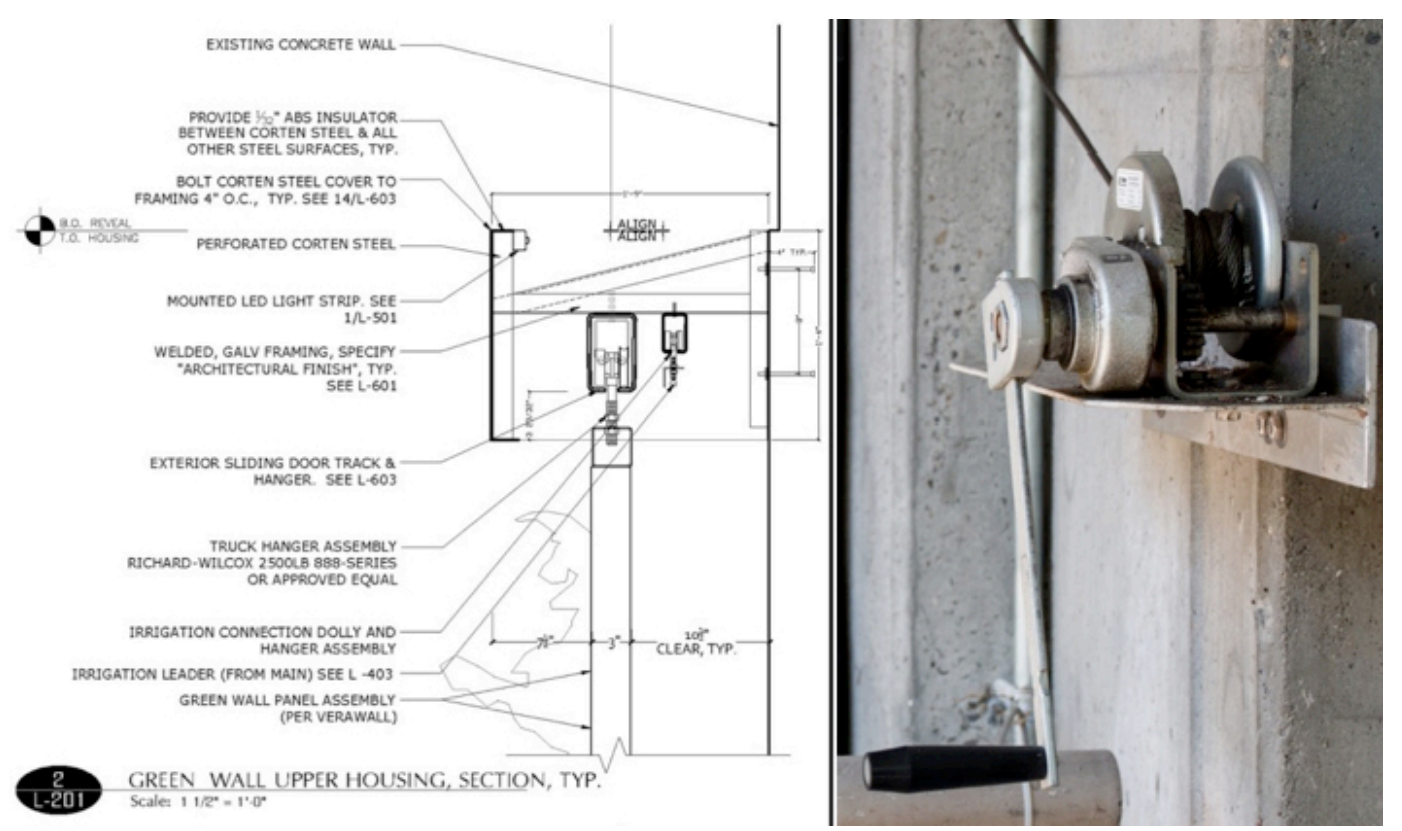

Figure 3: Truck hanger assembly detail that allows the Gould Hall Green Wall to move side to side and tuck behind the adjacent balcony (left) and photo of constructed balcony hand crank that moves the green wall panels (right). The assembly is designed to hold up to $1250 \mathrm{lbs}$.

A rubber guide track roller assembly at the bottom back protects the existing concrete building wall while allowing for easy horizontal gliding, on the set of rubber wheels. These 
wheels also hold the panel at a consistent distance from the building wall to maintain its verticality.

\section{Water and Electricity}

The track is concealed behind a perforated valance of Corten steel, which also houses LED rope lights that shine through the speckled voids and reinforces the horizontal geometry of the 1970s Brutalist building both day and night. The valance simultaneously conceals the irrigation line that distributes rainwater collected from the building's rooftop cisterns tucked beneath the balcony. To ensure that soil for the semi-hydroponic system remains consistently moist, rainwater (with potable water backup) is pumped upwards twice daily to drip irrigation lines and emitters evenly spaced from top to bottom on both walls. Sensors provide information on soil moisture levels and remote controls allow monitoring and irrigation regime adjustment. A water trough on the lower valance catches excess irrigation water from the top wall panel and carries it through a downspout to the yews below, and is a favored feature for birds who use it for perching, bathing and drinking. (Figure 4)

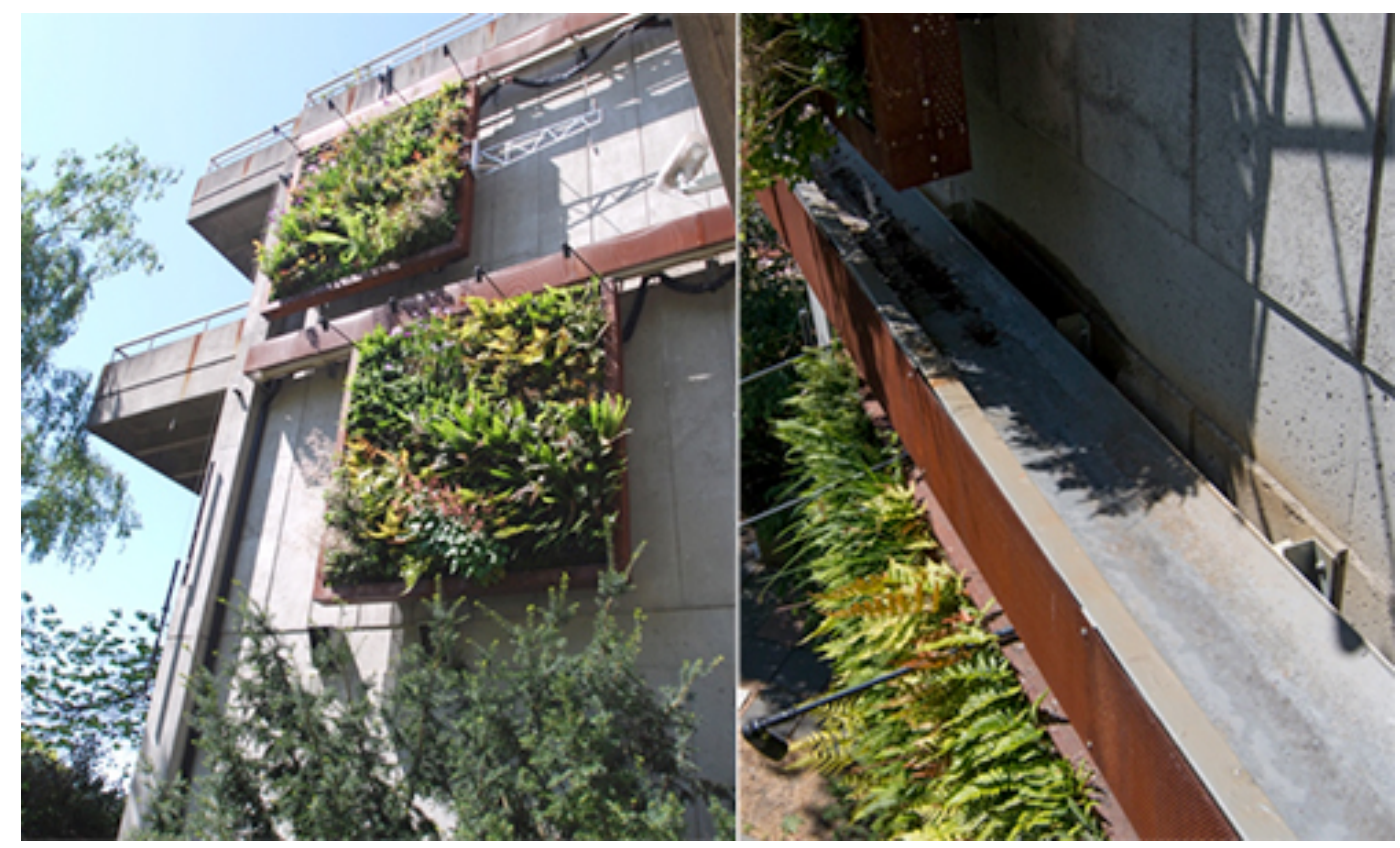

Figure 4: Track mechanism and perforated valance that conceals utilities (left) and a water trough on top of the lower valance to capture excess irrigation (right).

\section{Plant Support System and Growth Media}

The two panels located on an east-facing wall receive soft morning light. They grow over 500 plants in Solterra System's Vera Wall felt-fabric pockets supported and held by the Corten frame. The pockets are filled with a specialized lightweight ( $<10 \mathrm{psf}$ saturated), highcompost potting soil mix into which young nursery-grown plants have been inserted. (Figure 5) The system is designed so that plant roots grow into the fabric and between the pockets, thereby stabilizing the plants and holding them in place as the wall is moved or buffeted with winds. 


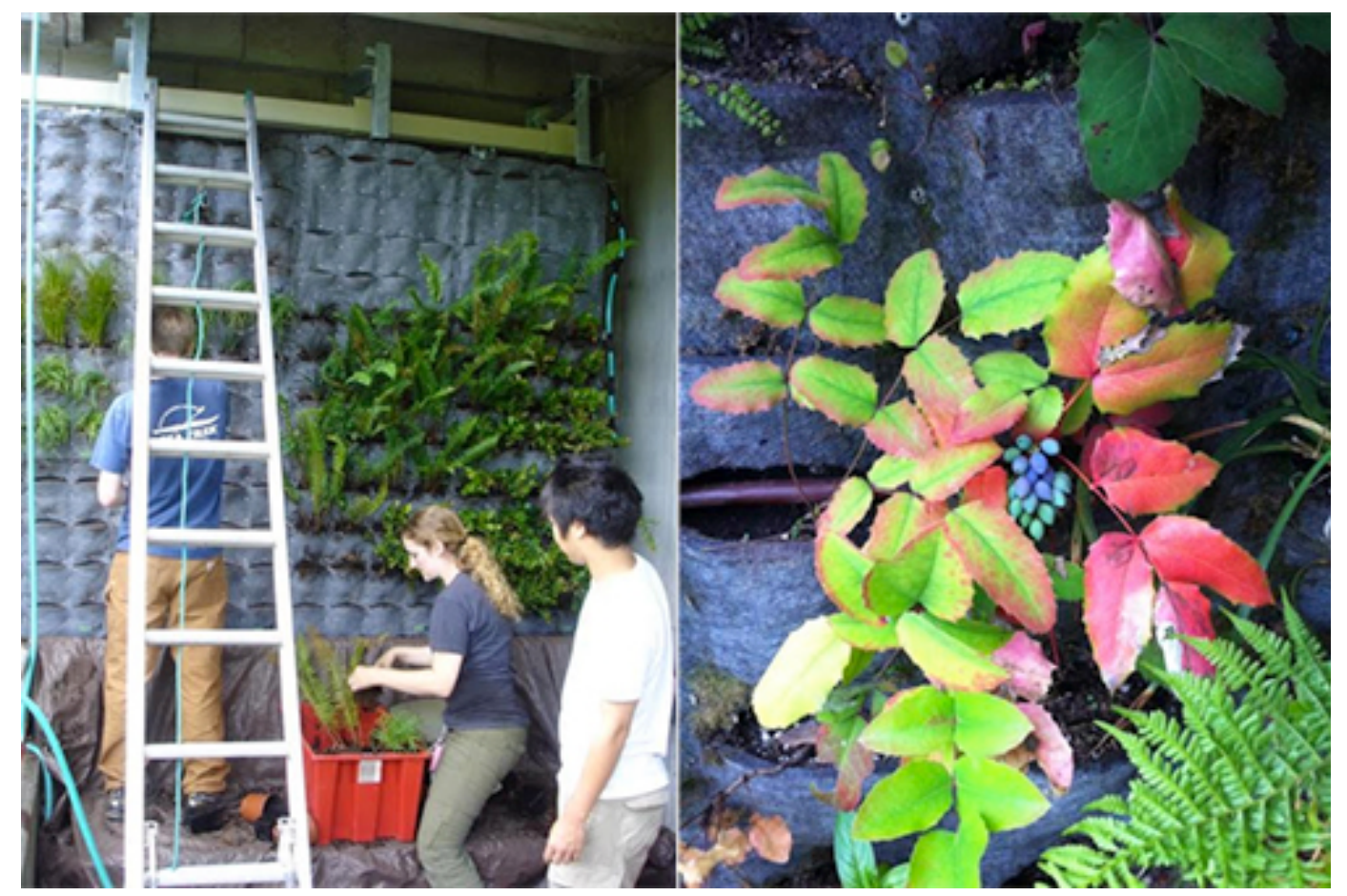

Figure 5: Plant installation process showing Vera Wall fabric pockets (left), close-up of pockets, lightweight soil and drip irrigation system (right).

\section{Habitat}

Plant species are a mix of Pacific Northwest natives and non-natives and selected for their suitability for an east-facing aspect, tolerance to frost and various moisture regimes, and their specific characteristics to support birds and insects (i.e. berries, flowers, depth for nesting), grow penetrating roots for strong green wall attachment, adaptability and visual color and textural qualities. Native sword ferns (Polystichum munitum) planted on diagonals across both panels supplied the planting design structure, with other species of ferns, grasses, groundcovers, and native salal (Gaultheria shallon), evergreen huckleberry (Vaccinium ovatum), and creeping Oregon grapeholly (Berberis repens), among others, supporting this pattern and providing color and textural contrast. The maintenance regime restricted movement of the green wall panels during nesting season and left deciduous winter vegetation intact, especially grasses, for nesting materials.

\section{Weight}

The weight of the green wall needed to be engineered with the design of the moveable system and the ability of the existing building structure to support it. The cumulative weight of each 10 ' x 10' panel was estimated at 1250 pounds, including $10 \mathrm{psf}$ for the saturated soil and plants, and a maximum of 250 pounds for the panel and its structural and mechanical components; this weight was considerably less than the estimated capacity of the 8-inch thick concrete wall to support the panels in a seismic event. Brackets and attachment hardware supporting the truck assembly was engineered using the estimated weight of the panel system, evenly distributing stresses through a series of galvanized framing anchors spaced five feet apart. 


\section{Cost}

The combined system of the moveable panels, water harvesting system with two cisterns, irrigation, lighting, design (an extensive year-long student-faculty-staff process), monitoring equipment, administration and two-year maintenance contract cost approximately $\$ 100,000$ in 2012, or approximately $\$ 500$ per face foot.

\section{Action and Agent}

While the design team originally considered a motorized device to move the wall back and forth, the system was ultimately simplified through the use of a manual hand crank that would far outlast an automatic device and with less cost. Moving the irrigation and lighting cables along with the wall was a challenge. A flexible garden hose hung from the sliding trucks and track assembly conveys water from the cisterns below to the top mainline for the drip irrigation in each green wall. While the LED track lights are affixed to the perforated Corten valance, additional LED spotlights highlight the plant material and were bundled in retractable flexible electric wiring alongside the irrigation lines (Figure 6). Careful consideration was made to assure that these utility systems would not cross or get tangled in the wall during transit.

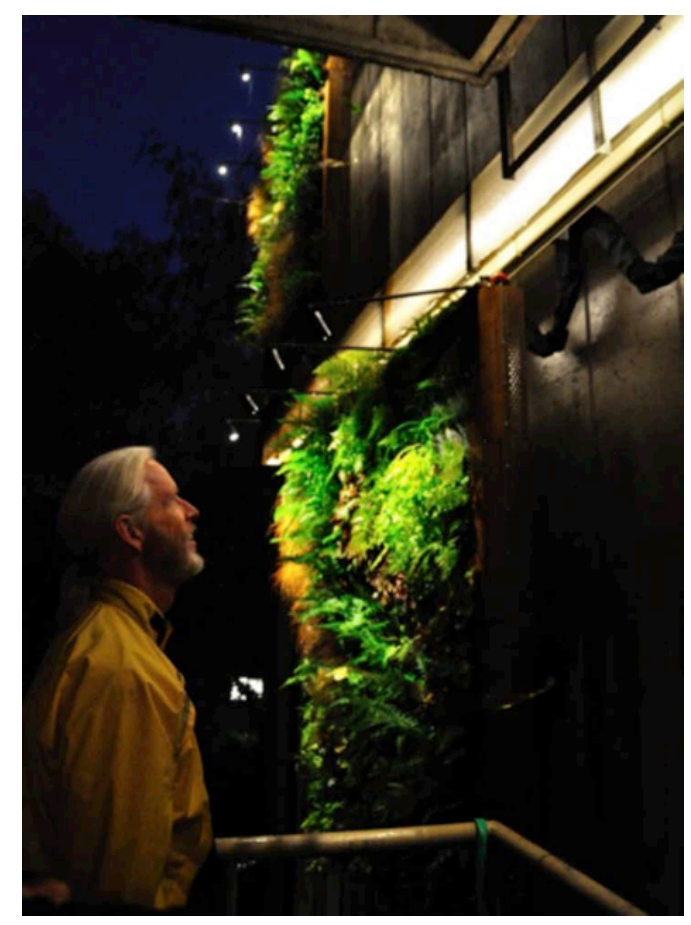

Figure 6: LED rope lights are affixed to the perforated valance and shine through the speckled voids to artfully reinforce the horizontal building geometry. LED spotlights highlight plant material while providing safety lighting. Electric wiring bundles in a retractable sleeve alongside irrigation lines.

\section{Gould Hall Sliding Wall Prototype Observations}

\section{Access, Movement Systems}

The kinetic mechanism of the walls has performed smoothly over the five years since construction, and has facilitated a current research study of benefits of the Gould Hall Green 
Wall. The wall is wheeled to the balcony 1-5 times per week to inspect it for insect use, to document bird nest construction (after nesting season), and to capture data from thermal sensors that have been installed to test the walls' effect on ambient outdoor and indoor air temperatures. (These results will be reported in a future article documenting the study). If properly oiled, the hand crank requires very little effort (easy for the young and old), makes minimal noise, and the wall can be moved from one end to the other in under a minute. The moveable system has produced no electrical and irrigation line problems.

The sliding track was designed at a $1 \%$ slope so that the green wall panels would slide down the track and away from the balcony when the hand crank was turned counter clockwise to create slack in the line. However, halfway into the construction process, the design team discovered that the weight of the wall itself worked against the pull of gravity and the wall was not sliding away from the balcony with the reverse turn of the hand crank; consequently counter weights were added on the end of the track wires to provide the needed counterbalance. Again, 5-years after this adjustment, the system has had no problems with gravity pull for easy placement along the track. Minimal plant material has been swept out of the gutter yearly, however there were no problems with the plants growing into the track system.

\section{Water}

The ability to crank the wall to the balcony has also been critical in maintaining the irrigation system -- ever the bane of any garden system and essential to the survival of the semihydroponic system of a living wall and for replacing plants, weeding, and installing habitat accoutrements such as bird perches. As plant material grew, weather patterns changed and moisture levels were tracked, so the project team took an adaptive management approach altering irrigation frequency and intensity. Additional irrigation lines and larger emitters compensated for low-pressure issues and achieved even coverage from top to bottom of the panels. This accounted for more exposure to wind at the top and aggregation of water flow at the bottoms of the panels. The moveable design allowed for frequent check of moisture levels, so that alterations could also be made in response to extreme high and low temperatures and recent changing weather in Seattle. It also helped during repair of inevitable leaks at fitting junctions. Additionally, cranking the panels over to the balconies allowed manual hand watering on hot days when the automatic irrigation system was not functioning correctly.

\section{Plant Growth and Habitat}

Over the course of four years we tracked plant species performance and survival. The aforementioned Pacific Northwest native species generally proved most resilient, with some of the colorful exotics such as Heuchera spp. succumbing to root pests. Species with shallow roots (e.g. Sedum spp.) tended to fall out of the wall requiring replacement; this was unrelated to moving the wall, but related to gravity and less robust root systems in these species. Observations indicate that birds and insects do indeed use the kinetic living walls, including nesting (Figure 7) and providing new habitat on an otherwise blank wall with no food, shelter, or reproductive spaces. During the nest-building, egg-laying and rearing seasons the 
wall was not moved. More specific plant and habitat results will be reported in a separate paper.

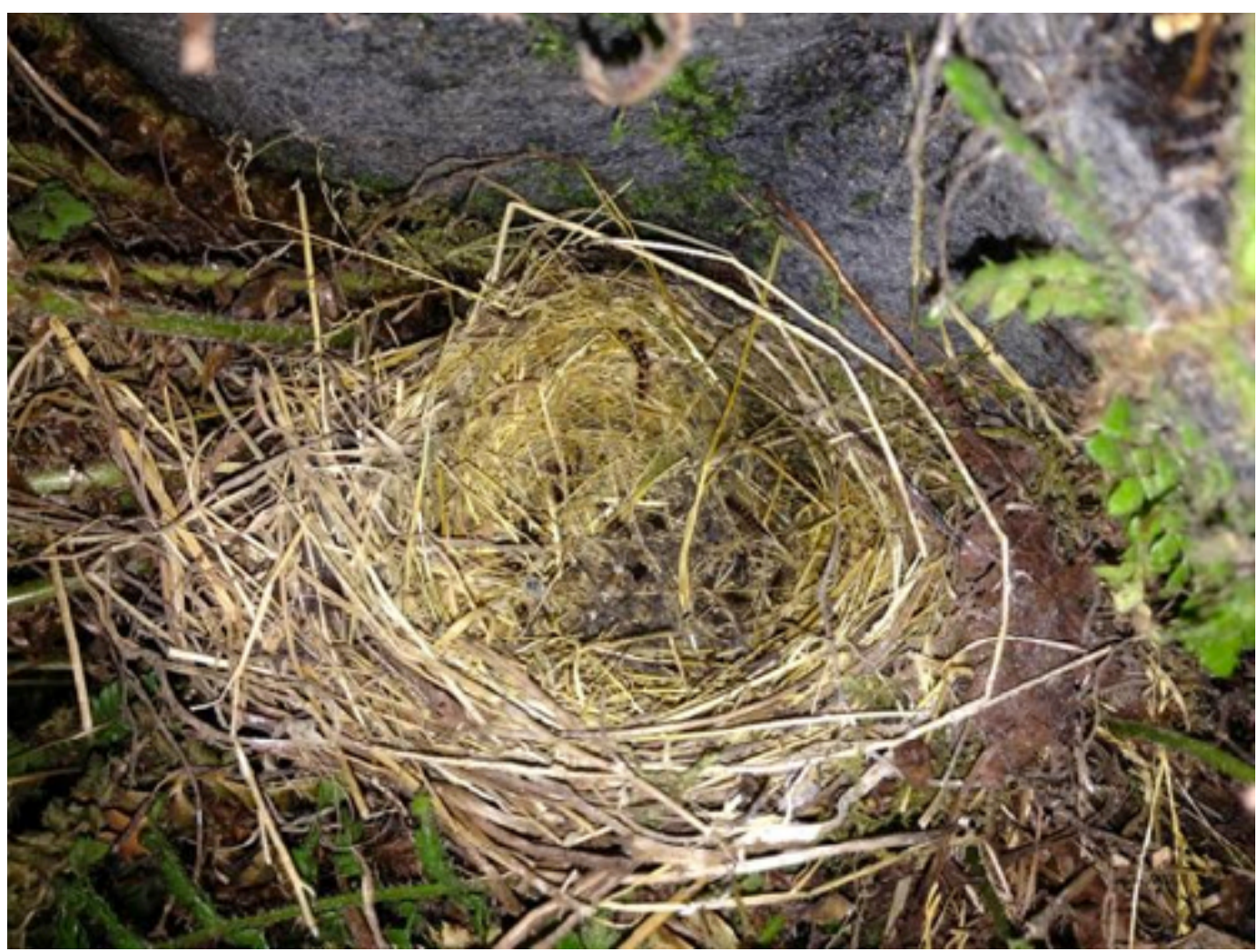

Figure 7: Image of an Oregon Junco nest built within the thick vertical vegetation, with the nest attached to the fabric planting pockets, where a successful brood was raised.

\section{Action and Agent}

In addition to the functional benefits of the moveable living wall panels, their positions have been modified to offer visual variety through the seasons and year. The panels can be positioned as vertically aligned or offset, in a multitude of patterns. Since the walls can be viewed from the street as well as the garden, this variety adds interest and dynamic change to the visual contribution of the walls and the otherwise blank building façade. The act of physically moving the panels to the balcony via the crank also actively engages people-- it's fun! -- and allows up-close, first-hand, tactile interaction with the living wall's plants and insects, as well as its construction system. The design team has shown it many times to classes and visitors, and it consistently evokes delight. (Figures 8-9) Such a dynamic approach to living walls on multi-family residential structures would encourage individuals to produce personalized units and promote interesting, ever-changing facades. 


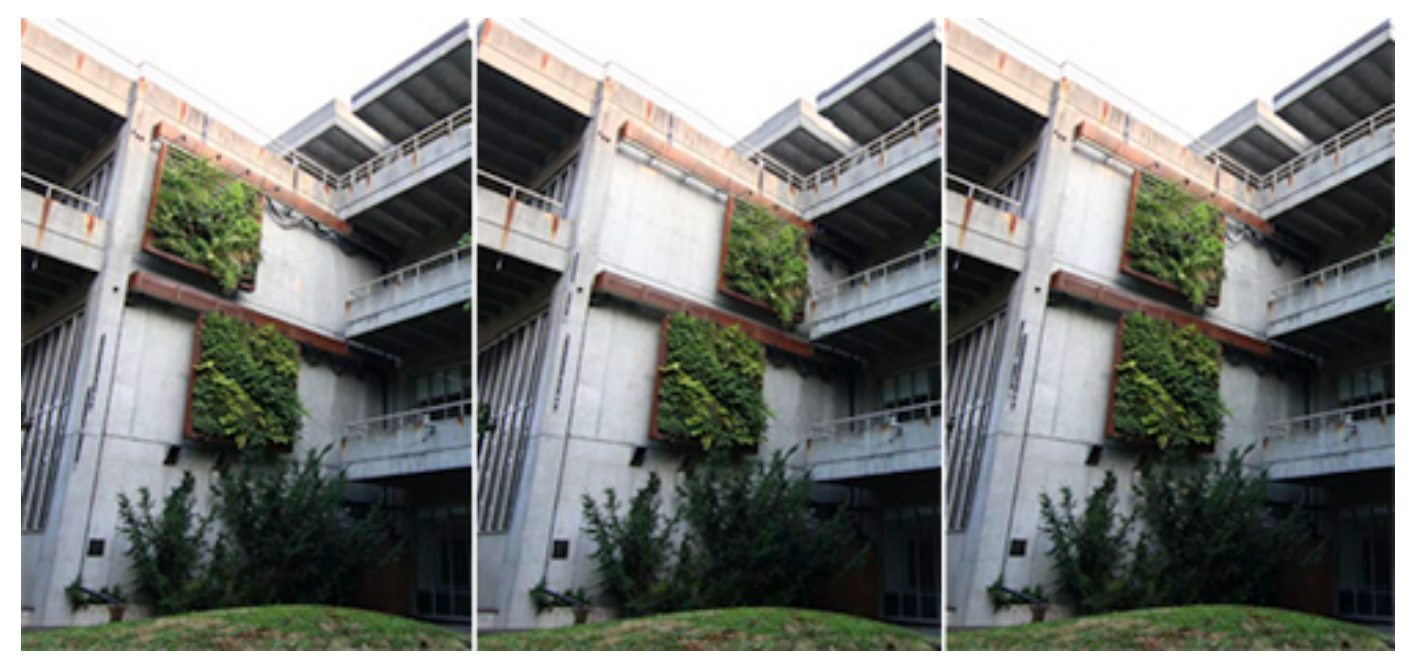

Figure 8: The panels can be positioned in a multitude of patterns to offer visual variety.

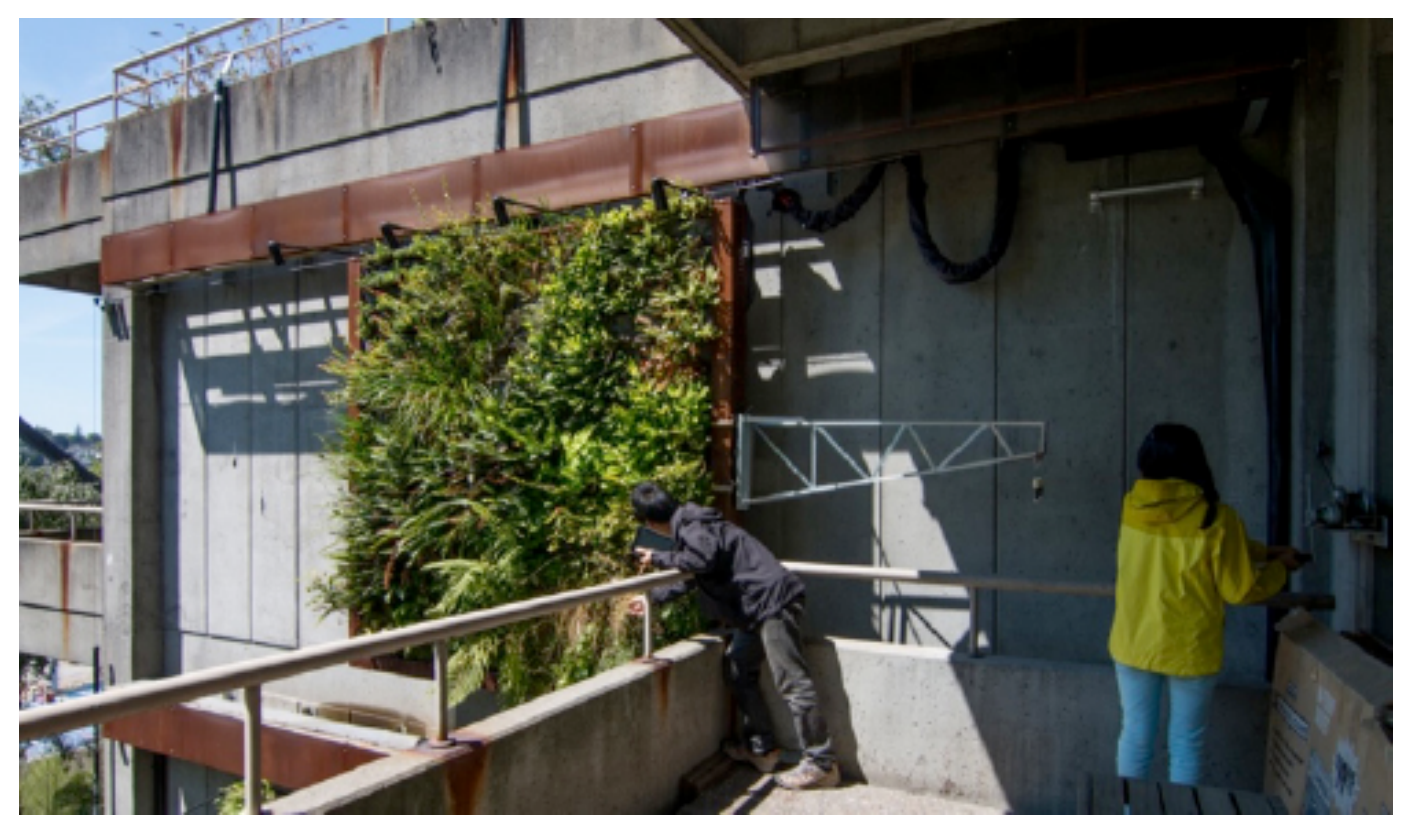

Figure 9: The walls move to tuck behind the balcony to allow up close, first-hand tactile interaction with the living wall. The height of the green wall panel was dictated by the height between floors/balconies, and the width by the depth of the balcony so all parts of the green wall would be in reach when wheeled in. (The aluminium arm is a temporary addition to hold experimental "control" thermal sensors.)

\section{RECOMMENDATIONS FOR KINETIC LIVING WALLS}

As illustrated in the Potential Applications section, and exemplified in the Gould Green Wall, the kinetic living wall prototype may take many different forms. The experience of fully designing, constructing, maintaining and observing the Gould Green Wall indicates several essential technical considerations. The list below also includes some ideas for various responses to these requirements:

- Access: Positions for maintenance, harvesting, monitoring and enjoying the wall's plantings. 
- Movement systems: Track, hinge, folding arm, scissor bracket, rotating carousel, wheels, etc. all need to work together in an integrated system.

- Water (and potentially electricity): Integration of irrigation and electrical lines: Flexibility to move with wall, and careful organization to avoid tangling of lines. Capture and control of excess irrigation water. Regular monitoring of moisture levels and remote adjustment of irrigation regimes.

- Plant and Growth Media Support System: Select materials and plants responsive to local light, heat and wind conditions, and to encourage secure rooting into the substrate and stabilization of soil media. Soil media should be lightweight and simultaneously water-retentive and well-draining, such as is provided by a mixture of volcanic pumice and organic material.

- Habitat: Plant choice to support urban wildlife. Careful sensitivity to not disturb birds during nesting season through moveable features

- Weight (as in any additions to a building wall): Anticipate measured weight additions, and distribute stresses evenly. Provide consistent stability in all positions; anticipate angles.

- Cost: Anticipate maintenance costs and adjustments of designs in an adaptive management strategy

- Action and Agent: Pulled (crank or wheel) vs. pushed (motor or stick). Counterweight vs. or plus use of gravity. Horizontal vs. vertical movement of the wall. Human controlled vs. motorized; Human initiated vs. light or motionsensor initiated.

Integrating kinetic living systems into intensifying urban environments invites new and creative design opportunities. Providing the ability to maintain and monitor living walls through moveable elements can help to ensure plant component survival. Installing moveable living walls so that that they are accessible to urban dwellers can provide the benefits of equitable access to nature for those who otherwise don't have such opportunities, including the mental health and recreational benefits of gardening, and the ability to grow and harvest food. Moveable living wall panels could provide the multiple benefits of shading, insulating and cooling, providing cost-effective and energy-efficient human comfort within buildings, and the environmental benefits of cooling the outdoor air of the heat-retaining urban hive. A light or motion-controlled system can be used so that living walls can move to where they are most needed or to obtain protection or sunlight, throughout the day or between seasons. The kinetic aspect of living walls not only allows access flexibility for maintenance, but also, and importantly, the personal enjoyment and educational benefits of direct interaction with the natural world. Such living walls may also provide opportunities for urban dwellers to personalize and create identity and dynamic expression in an otherwise anonymous and static built environment. The possibilities are limited only by the imagination and demand new ways of applying green wall design to the urban context. Living walls, like living things, can move.

Please see a video of the Gould Hall Green Wall being moved, at: https://youtu.be/HhQpOp7jkDI 


\section{ACKNOWLEDGEMENTS}

The design and construction of the Gould Hall Green Wall involved over 60 students, faculty and staff, with the authors of this paper as Co-PIs in the Green Futures Research and Design Lab. We acknowledge in particular the student design team including David Tomlinson, Chris Ewing, Katie Hunt, Laura Poulin, and Matt Chism, our partner contractor, SolTerra Systems, especially Angela Jones, and University of Washington Facilities and Brian Davis. Photo and video credits go to Harley Pan, and drawing credits go to Leann Andrews and David Tomlinson. A special thank you to our partners including the University of Washington Campus Sustainability Fund, Office of Sustainability, Gilbert Wong, UW College of Built Environments and UW Department of Landscape Architecture.

\section{LITERATURE CITED}

Azkorra, Z., G. Pérez, J. Coma, L. Cabeza, S. Bures, J. Álvaro, A. Erkoreka,, and M. Urrestarazu, M. 2015. "Evaluation of green walls as a passive acoustic insulation system for buildings." Applied Acoustics (89):46-56.

Beatley, T. 2011. Biophilic Cities: Integrating Nature Into Urban Design and Planning. Washington, DC: Island Press.

Bergmann, S. 2015. Pollinator Pathway. [Last accessed 15/01/2015]. http://www.pollinatorpathway.com.

Chen, Q., B. Li, and X. Liu, 2013. "An experimental evaluation of the living wall system in hot and humid climate." Energy and Buildings (61):298-307.

Francis, R. 2011. "Wall ecology: A frontier for urban biodiversity and ecological engineering." Progress in Physical Geography 1(35):43-63.

Kellert, R., J. Heerwagen, and M. Mador. (Eds.) 2008. Biophilic design: The Theory, Science, and Practice of Bringing Buildings to Life (pp.3-19). Hoboken, NJ: Wiley \& Sons, Inc.

Lianga, T., W. Hiena, and S. Jusuf. 2014. "Effects of vertical greenery on mean radiant temperature in the tropical urban environment." Landscape and Urban Planning (127):52-64.

Oberndorfer, E., J. Lundholm, B. Bass, R. Coffman, H. Doshi, N. Dunnett, S. Gaffin, M. Kohler, K. Liu, B. Rowe, 2007. "Green roofs as urban ecosystems: ecological structures, functions, and services." BioScience (57):823-833. http://bioscience.oxfordjournals.org/content/57/10/823.full

Pulselli, R., F. Pulselli, U. Mazzali, F. Peronb, and S. Bastianoni. 2014. "Energy based evaluation of environmental performances of living wall and grass wall systems" Energy and Buildings (73):200211.

Safikhani, T., M. Baharvand, A. Abdullah, and D. Ossen. 2014. "A review of energy characteristic of vertical greenery systems." Renewable and Sustainable Energy Reviews (40):450-462.

Sutton, R. 2014. "Aesthetics for green roofs and green walls." Lincoln Nebraska: University of Nebraska Lincoln Digital Commons. (Last accessed 02-02-2017)

http://digitalcommons.unl.edu/cgi/viewcontent.cgi?article=1018\&context=arch land facultyschol

Williams, C. 2010. Biodiversity for Low and Zero Carbon Buildings: A Technical Guide for New Build. London: RIBA Publishing. 
Wolf, K., S. Krueger, and M. Rozance. 2014. "Stress, wellness and physiology - A literature review." In: Green Cities: Good Health College of the Environment, University of Washington. (Last Accessed 02/12/2017) http://www.greenhealth.washington.edu

Wong, N., A. Tan, P. Tan, K. Chiang, N. Wong. 2010. "Acoustics evaluation of vertical greenery systems for building walls." Building and Environment (45):411-420. 